\title{
1.25-Gb/s transmission over an access network link with tunable OADM and a reflective SOA
}

Citation for published version (APA):

Urban, P. J., Pluk, E. G. C., Laat, de, M. M., Huijskens, F., Khoe, G. D., Koonen, A. M. J., \& Waardt, de, H. (2009). 1.25-Gb/s transmission over an access network link with tunable OADM and a reflective SOA. IEEE Photonics Technology Letters, 21(6), 380-382. https://doi.org/10.1109/LPT.2008.2012171

DOI:

10.1109/LPT.2008.2012171

Document status and date:

Published: 01/01/2009

\section{Document Version:}

Publisher's PDF, also known as Version of Record (includes final page, issue and volume numbers)

\section{Please check the document version of this publication:}

- A submitted manuscript is the version of the article upon submission and before peer-review. There can be important differences between the submitted version and the official published version of record. People interested in the research are advised to contact the author for the final version of the publication, or visit the $\mathrm{DOI}$ to the publisher's website.

- The final author version and the galley proof are versions of the publication after peer review.

- The final published version features the final layout of the paper including the volume, issue and page numbers.

Link to publication

\section{General rights}

Copyright and moral rights for the publications made accessible in the public portal are retained by the authors and/or other copyright owners and it is a condition of accessing publications that users recognise and abide by the legal requirements associated with these rights.

- Users may download and print one copy of any publication from the public portal for the purpose of private study or research.

- You may not further distribute the material or use it for any profit-making activity or commercial gain

- You may freely distribute the URL identifying the publication in the public portal.

If the publication is distributed under the terms of Article 25fa of the Dutch Copyright Act, indicated by the "Taverne" license above, please follow below link for the End User Agreement:

www.tue.nl/taverne

Take down policy

If you believe that this document breaches copyright please contact us at:

openaccess@tue.nl

providing details and we will investigate your claim. 


\title{
1.25-Gb/s Transmission Over an Access Network Link With Tunable OADM and a Reflective SOA
}

\author{
P. J. Urban, Student Member, IEEE, E. G. C. Pluk, M. M. de Laat, F. M. Huijskens, G. D. Khoe, Fellow, IEEE, \\ A. M. J. Koonen, Fellow, IEEE, and H. de Waardt, Member, IEEE
}

\begin{abstract}
The emerging broadband services and the avalanchelike growth of the broadband subscribers result in the intensification of data traffic in access networks. This drives the development of last-mile technologies to support multiservice provision on high bit-rate-capable reconfigurable networks. In this letter, we present the first transmission experiments carried out on the testbed of a hybrid wavelength-division-multiplexing/timedivision-multiplexing access network based on cost-efficient elements like an integrated optical add-drop multiplexer and a reflective semiconductor optical amplifier. We successfully transmit two 1.25-Gb/s wavelength channels over $26-\mathrm{km}$ standard single-mode fiber carrying data to and from the user.
\end{abstract}

Index Terms-Optical add-drop multiplexer (OADM), passive optical networks, reflective semiconductor amplifier.

\section{INTRODUCTION}

$\mathbf{T}$ HE telecommunication world is forced to search for nearfuture and future-proof technological solutions in the access domain [1] as the traffic load and the number of broadband subscribers is growing. The emphasis is put on symmetrical high bit-rate transmission and network reconfigurability to adapt the bandwidth to users' demands, network reliability and survivability to reduce operational expenditures and network coverage, scalability, and on-chip integration to reduce capital expenditures.

The network presented here comprises the above features and provides high bandwidth on-demand in a cost-efficient manner thanks to integratable elements such as an optical add-drop multiplexer (OADM) [2] and a colorless optical network unit (ONU) [3]. The OADM enables remote network reconfiguration as a result of wavelength channel switching. The centralized light generation and remote continuous-wavelength $(\mathrm{CW})$ modulation omits the need for a light source in the ONU. ON-OFF keying $(\mathrm{OOK})$ is applied in both directions which requires simple direct receivers.

\footnotetext{
Manuscript received September 11, 2008; revised December 20, 2008. First published February 02, 2009; current version published March 11, 2009. This work is done in the Freeband BBPhotonics Project. Freeband is sponsored by the Dutch Government under Contract BSIK 03025.

P. J. Urban, F. M. Huijskens, G. D. Khoe, A. M. J. Koonen, and H. de Waardt are with the COBRA Institute, Eindhoven University of Technology, NL-5600MB Eindhoven, The Netherlands (e-mail: p.j.urban@tue.nl; f.m.huijskens@tue.nl; g.d.khoe@tue.nl; a.m.j.koonen@tue.nl; h.d.waardt@tue. nl).

E. G. C. Pluk and M. M. de Laat are with the Genexis BV, NL-5652AC Eindhoven, The Netherlands (e-mail: e.pluk@genexis.nl; m.delaat@ genexis.nl).

Color versions of one or more of the figures in this letter are available online at http://ieeexplore.ieee.org.

Digital Object Identifier 10.1109/LPT.2008.2012171
}

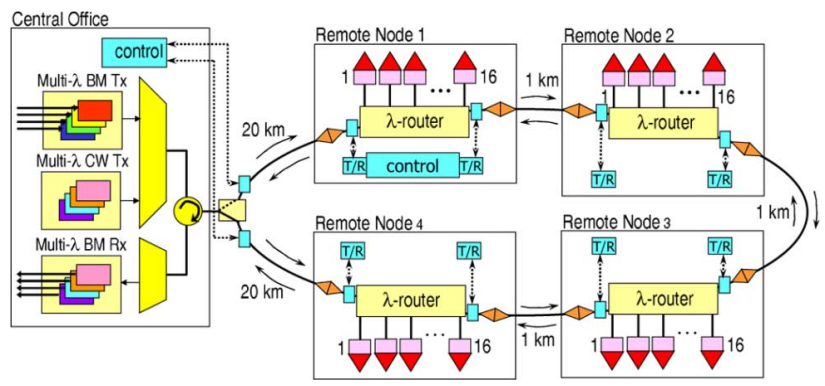

Fig. 1. BBPhotonics access network architecture. a)

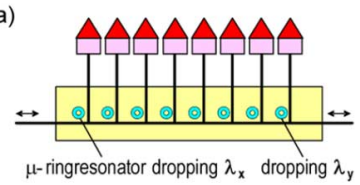

b)

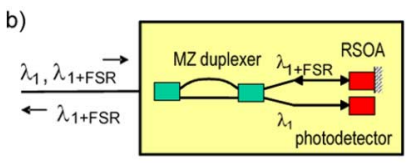

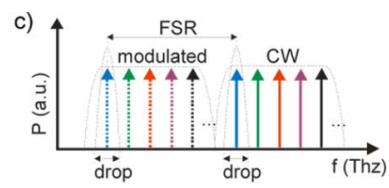

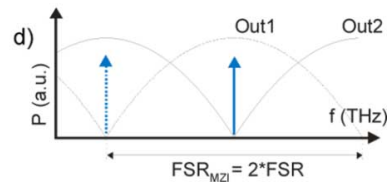

Fig. 2. (a) OADM. (b) ONU. (c) Wavelength panel at OADM. (d) Wavelength panel at ONU.

\section{NETWORK ARCHITECTURE}

The BBPhotonics architecture [4] is a dynamically reconfigurable access network which connects 16 ONUs to every remote node (RN). All four RNs are connected by a standard single-mode fiber (SSMF) with a central office (CO) (Fig. 1).

The CO transmits eight wavelength channel pairs $\lambda_{i}$ and $\lambda_{i}+$ FSR, where FSR is the free spectral range of the OADM equal to integer multiple of $50 \mathrm{GHz} . \lambda_{i}$ carries the downstream data [nonreturn-to-zero (NRZ)] to be received by the end-user, and $\lambda_{i}+$ FSR is the CW carrier to be modulated at the ONU. Such an FSR-coupled wavelength pair is dropped at the same output port of the OADM. The FSR value allows us to apply several ITU-T standard wavelength channels (50-GHz intervals between $\lambda_{1}, \lambda_{2}, \ldots$ and $\lambda_{1}+$ FSR, $\lambda_{2}+$ FSR,$\ldots$ ) and this enables utilization of commercially available elements (e.g., arrayed waveguide grating (AWG) at $\mathrm{CO}$ ) [Fig. 2(c)]. If the bandwidth demands are higher, the amount of wavelength channels can be increased by a hardware upgrade at the $\mathrm{CO}$ only. The amount of burst-mode receivers at the $\mathrm{CO}$ corresponds to the number of upstream wavelength channels. For protection function a switch is placed at the $\mathrm{CO}$. Its state depends on the point of a fiber break in the ring. For network management 100 Base-X protocol is used [5] and the channel $(1310 / 1490 \mathrm{~nm})$ is coupled 


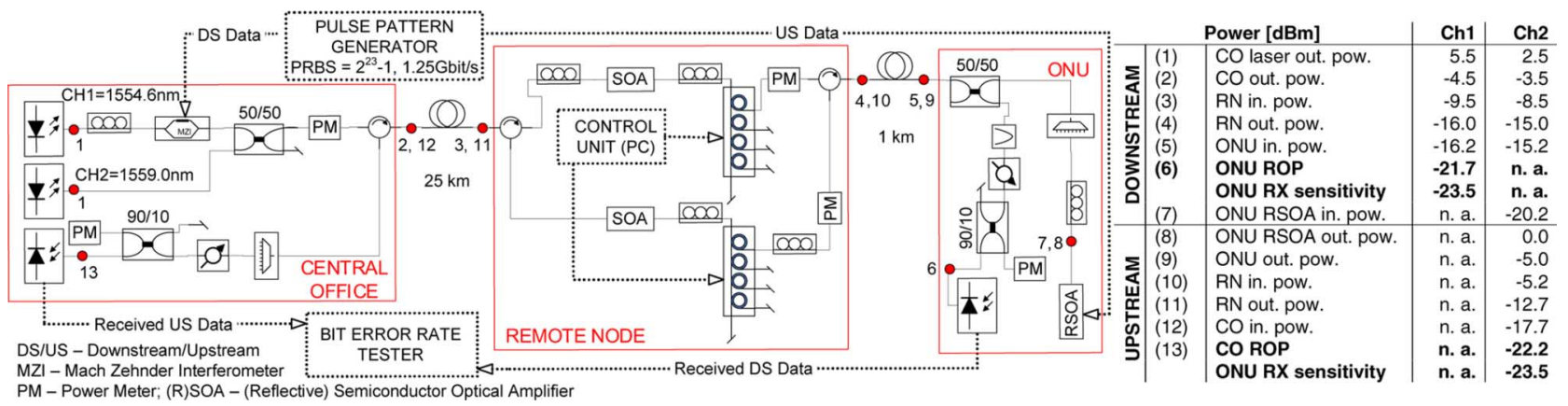

Fig. 3. Proof-of-principle testbed.

into the ring via coarse wavelength-division multiplexers at the $\mathrm{CO}$ and RNs.

The main part of the RN is an OADM, which is an integrated structure of individually controlled thermally tunable microring resonators. An example of an eight-port device is shown in Fig. 2(a). The temperature dependency of the refractive index is used to apply a phase shift to the optical field and as a result tune the resonant frequency. The switching time, which is needed to achieve maximum throughput (maximum correctly received UDP packets) again after a microring is tuned from one channel to the other $(50-\mathrm{GHz}$ wavelength grid) is $6 \mathrm{~ms}$. This will not be noticeable even for real-time applications (i.e., VoIP), where packets contain 10-20 ms of voice data. Using the OADM, a single wavelength pair can be dropped to one (PtP) or multiple users (time-division-multiplexing passive optical network). The latter case is achieved by detuning a ring with $5-10 \mathrm{GHz}$ from the broadcast wavelength channel which results in drop-and-continue operation of the ring resonator. The required power supply for the $\mathrm{RN}$ is provided by a dedicated connection to the public electric lines as for existing fiber-tothe-node/premise networks [6].

The integrated ONU [Fig. 2(b)] contains a tunable Mach-Zehnder interferometer (MZI) with FSR corresponding to the double FSR of the OADM [Fig. 2(d)] so any FSR-coupled wavelengths are decoupled at the two outputs of the MZI. The ONU is equipped with a photodetector to receive the downstream data and a reflective semiconductor optical amplifier (RSOA) to transmit the upstream data (NRZ). Besides providing gain and modulation at the same time, the RSOA can operate at any wavelength in the $C$-band, because of the broad optical bandwidth. A novel solution for ONU capable of providing $10 \mathrm{~Gb} / \mathrm{s}$ was suggested in [4].

The RSOA ${ }^{1}$ and the MZI [7] as well as the OADM [2] can be made polarization-independent.

\section{Testbed Structure}

A testbed contains a transmission link from $\mathrm{CO}$ via $\mathrm{RN}$ to ONU and backwards over a single fiber, as shown in Fig. 3.

The CO consists of two lasers generating optical carriers for downstream and upstream data transmission. Optionally (not included in Fig. 3), the channels are phase-modulated in the $\mathrm{CO}$, which will be discussed in Section IV. The receiver part of the $\mathrm{CO}$ consists of an AWG, an attenuator for bit-error rate (BER) versus received optical power (ROP) measurement, power tap to measure ROP, and a commercial $1.25-\mathrm{Gb} / \mathrm{s}$ receiver.

${ }^{1}$ CIP Technologies.
The RN is composed with the OADM providing four add-drop ports (the $3-\mathrm{dB}$ bandwidth of $0.15 \mathrm{~nm}$ ) and it is driven by a PC. Due to the fact that this OADM is a prototype device, some parameters do not match the desired values. There is an FSR mismatch of around $30 \mathrm{GHz}$, which allows only one channel from the wavelength pair to be set to an ITU-T standard wavelength (upstream) and as a result only filters applied to that channel are fixed. The OADM reveals substantial insertion loss of around $15 \mathrm{~dB}$ and low return loss of $17 \mathrm{~dB}$. The last parameter significantly limits the performance of the system due to low signal-to-crosstalk ratio (SCR) at the receivers. To block the reflected power, two identical OADMs were applied together with two circulators to provide adding and dropping operations separately. To compensate for the excess loss in the $\mathrm{RN}$, semiconductor optical amplifiers (SOAs) are applied.

The ONU consists of a splitter, a tunable optical bandpass filter, an attenuator, a power tap, a commercial 1-G receiver, a fixed bandpass filter, and a multiple quantum-well RSOA. ${ }^{1}$

The power budget (Fig. 3) leaves around 1.8- and 1.3-dB margin for downstream and upstream directions, respectively. The applied total fiber span of $26 \mathrm{~km}$ comes close to the distance at which accumulated Rayleigh backscattering (RBS) power is the highest and severely influences the signal-to-noise ratio in bidirectional systems (typically $25-30 \mathrm{~km}$ ). However, there are cost-effective solutions to mitigate the backreflection by optical signal linewidth enhancement [8]. Here, we use external phase modulation which enhances the spectral width of the channel and, therefore, reduces coherence length. This leads to lower interferometric noise in the receiver.

\section{TRANSMISSION EXPERIMENTS}

The back-to-back (BtB) downstream measurement, as presented in Fig. 4 (no fiber span, black squares), showed around 0.3-dB ROP difference with respect to the reference curve (bold curve, the same for down- and upstream measurement), which is within the accuracy of the measurement. After inserting $25 \mathrm{~km}$ of the feeder fiber and $1 \mathrm{~km}$ of the distribution fiber (black triangles), ROP did not change.

The upstream received signal reveals around $2.5-\mathrm{dB}$ power penalty for a BtB (black rhombus). This is justified by two factors. The first one is the difference in the performance of the RSOA as a modulator and the MZ modulator which was used in the reference measurement. The former has much lower electrical bandwidth than the latter one. The low electrical bandwidth of the RSOA is a result of carrier lifetime, which causes a longer falling edge of the eye diagram and consequently eye symmetry and extinction ratio degradation. The 


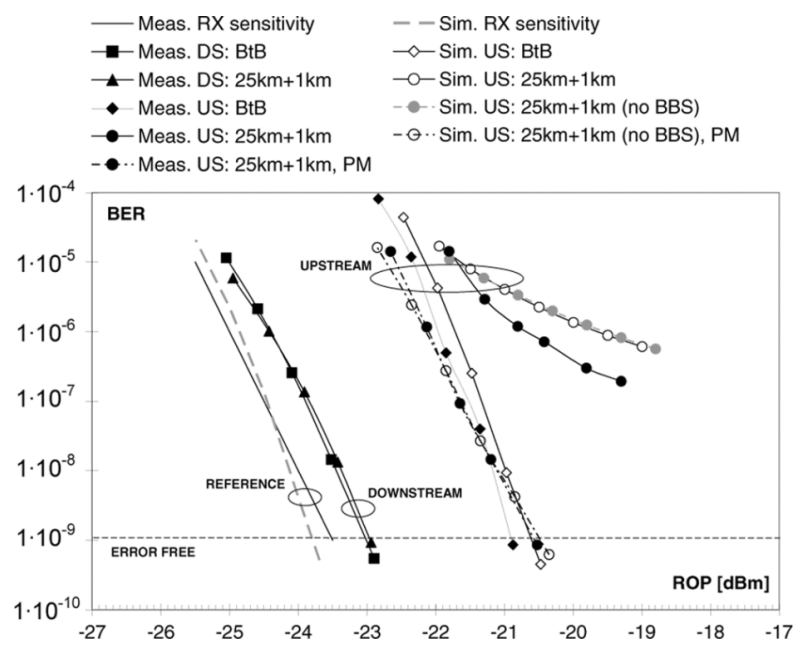

Fig. 4. Results of transmission experiments.

second factor is the amplified spontaneous emission (ASE) noise coming from the three cascaded SOAs which the signal experiences while passing the $\mathrm{RN}$, ONU, and $\mathrm{RN}$ again. This is not the case for the downstream data channel as it encounters the ASE source only once. The presence of the downstream does not influence the received upstream, as they are over $500 \mathrm{GHz}$ apart from each other. Inserting the fiber span causes error-floor and the required BER cannot be achieved (black circles) in the upstream transmission. This is due to the RBS and Brillouin backscattered (BBS) power propagating in both directions: towards ONU (RSOA performance degradation) and towards the OLT (receiver performance degradation).

To define the main distortion in the setup, we used the advantage of a simulation tool, ${ }^{2}$ where the corresponding setup was designed and the RBS and BBS could be switched ON-OFF. The rate-equation-based model of the RSOA with parameter values set accordingly to the data and the performance of the real device was used $^{1}$ (Table I). Only CW downstream data/upstream channel was simulated as it was said before the adjacent downstream data channel does not play a role in the received upstream signal. The power penalty in the simulations follow the same trend as in the measurements. It can be clearly seen that the error-floor is caused mainly by the RBS (white circles with solid line and grey circles with dashed line).

To reduce the influence of RBS, the linewidth of the signal was enhanced by means of phase modulation $(f=2.5 \mathrm{GHz}$, $\Delta \lambda_{3 \mathrm{~dB}}=50 \mathrm{pm}$ ). It is introduced by an external phase modulator after the 50/50 coupler in the CO. The phase modulation does not influence ROP of the downstream data channel, whereas for the upstream channel RBS-induced power penalty was completely eliminated (black circles with dashed line). Similar results for the same modulation conditions were obtained in the simulations (white circles with dashed-dotted line).

Additionally, in the simulations we verified the contributions of accumulation of ASE noise and the RSOA properties to the 2.5-dB penalty in the ROP of the upstream channel. After neglecting the RBS and BBS as well as the ASE noise of two SOAs placed in the RN (the ASE noise of the RSOA could not

${ }^{2}$ VPI TransmissionMaker.
TABLE I

RSOA SIMULATION PARAMETERS

\begin{tabular}{c|c}
\hline Parameter & Value \\
\hline \hline Active region length/width & $505.56 \cdot 10^{-6} \mathrm{~m} / 1.2 \cdot 10^{-6} \mathrm{~m}$ \\
\hline Tot. MQW active region thickness & $0.056 \cdot 10^{-6} \mathrm{~m}$ \\
\hline One-side SCH-region thickness & $0.059 \cdot 10^{-6} \mathrm{~m}$ \\
\hline MQW/SCH confinement factor & $0.045 / 0.2$ \\
\hline Group effective index/ $\alpha$-factor & $3.0 / 3.0$ \\
\hline Left/right facet reflectivity & $1 \cdot 10^{-7} / 3 \cdot 10^{-1}$ \\
\hline Fixed int. loss/linear mat. gain & $1000 \mathrm{~m}^{-1} / 6.7 \cdot 10^{-20} \mathrm{~m}^{2}$ \\
\hline Linear/bimol. recomb. coeff. & $0 \mathrm{~s}^{-1} / 1 \cdot 10^{-16} \mathrm{~m}^{3} \mathrm{~s}^{-1}$ \\
\hline Auger recomb. coeff. & $1.3 \cdot 10^{-41} \mathrm{~m}^{6} \mathrm{~s}^{-1}$ \\
\hline Transparency carrier density & $2.0 \cdot 10^{24}$ \\
\hline
\end{tabular}

be switched OFF due to virtual model restrictions), the 2.5-dB power penalty reduced with only $0.4 \mathrm{~dB}$. This means that the RSOA causes the major part of the power penalty. It is due to a combination of its lower $Q$-factor, electrical bandwidth, and extinction ratio with respect to the reference modulator, which was 6.1 and $8.1,10 \mathrm{~dB}$ and $13.5 \mathrm{~dB}$, and $1.5 \mathrm{GHz}$ and $9 \mathrm{GHz}$ for the RSOA and the MZM, respectively.

There is some minor discrepancy between the measurement and simulation results. The ASE noise was adjusted based on the measured noise figure of the real device and here some measurement uncertainty of $\pm 0.5 \mathrm{~dB}$ was involved. The other difference is due to the coherence-related aspects of the model. The chirp of the modeled RSOA was slightly lower with respect to the real device. This contributed to stronger interferometric interactions between the RBS and the signal power causing larger error-floor in the simulation.

\section{SUMMARY}

In this letter, we have presented transmission experiments performed on the testbed of a novel dynamically reconfigurable BBPhotonics access network. The results obtained for bidirectional transmission of $1.25-\mathrm{Gb} / \mathrm{s}$ wavelength channels over a 26-km SSMF RBS robust link with the colorless ONU and tunable OADM prove the feasibility of the concept.

\section{REFERENCES}

[1] M. J. O’Mahony, C. Politi, D. Klonidis, R. Nejabati, and D. Simeonidou, "Future optical networks," J. Lightw. Technol., vol. 24, no. 12, pp. 4684-4696, Dec. 2006.

[2] E. J. Klein et al., "Densely integrated microring resonator based photonic devices for use in access networks," Opt. Express, vol. 15, no. 16, pp. 10346-10355, Aug. 2007.

[3] L. Xu et al., "InP-based monolithic integrated colorless reflective transceiver," in Proc. ECIO 2008, Eindhoven, The Netherlands, Paper FrPD4.

[4] P. J. Urban et al., "1.25-10 Gbit/s reconfigurable access network architecture," in Proc. ICTON 2007, Rome, Italy, Paper Th.B1.6.

[5] R. Roy, G. Manhoudt, and W. van Etten, "Bandwidth redistribution techniques for extended EPON based multi-wavelength networks," in Proc. ICTON 2007, Rome, Italy, Paper Mo.P.21.

[6] G. Keiser, FTTX Concepts and Applications.. Hoboken, NJ: Wiley, 2006.

[7] L. Xu et al., "InP based polarization insensitive tunable duplexer and integrated reflective transceiver," in Proc. ECIO 2007, pp. 1-4.

[8] P. J. Urban, A. M. J. Koonen, G. D. Khoe, and H. de Waardt, "Mitigation of reflection-induced crosstalk in a WDM access network," in Proc. OFC 2008, San Diego, CA, Paper OThT3. 